\title{
Melatonin contributes to the hypertrophic differentiation of mesenchymal stem cell-derived chondrocytes via activation of the Wnt/ $\beta$-catenin signaling pathway
}

\section{Melatonin promotes MSC-derived chondrocytes hypertrophy}

Xuan Wang ${ }^{1,2,3 \dagger}$, Tianwei He $e^{1,2,3 \dagger}$, Lei He $e^{1,2,3 \dagger}$, Bu Yang ${ }^{1,2,3}$, Zhongyu Liu ${ }^{1,2,3}$, Mao Pang ${ }^{1,2,3}$, Peigen Xie 1,2,3, Liangming Zhang ${ }^{1,2,3^{*}}$ and Limin Rong ${ }^{1,2,3^{*}}$ (D)

\begin{abstract}
Background: Hypertrophy is a critical process for chondrocyte differentiation and maturation during endochondral ossification, which is responsible for the formation of long bone and postnatal longitudinal growth. Increasing evidence suggests that melatonin, an indole hormone, plays a pivotal role in chondrogenesis. However, little is known about the effects of melatonin on the terminal differentiation of chondrocytes.

Methods: Mesenchymal stem cell (MSC)-derived chondrocytes generated by a high-density micromass culture system were induced to undergo hypertrophic differentiation. Melatonin-mediated hypertrophic differentiation was examined by reverse transcription polymerase chain reaction analysis (RT-PCR) analysis, histological staining and immunohistochemistry. Activation of the Wnt signaling pathway was evaluated by PCR array, RT-PCR, western blotting and immunofluorescence. XAV-939, a Wnt signaling pathway antagonist, was further used to determine whether the effect of melatonin on chondrocyte hypertrophic differentiation was mediated occurred by activation of Wnt signaling pathway.

Results: Histological staining showed melatonin increased chondrocyte cell volume and the expression of type $X$ collagen but decreased the expression of type II collagen compared with the control group. RT-PCR showed that melatonin significantly up-regulated the gene expressions of biomarkers of hypertrophic chondrocytes, including type X collagen, alkaline phosphatase, runt-related transcription factor 2, Indian hedgehog and parathyroid hormonerelated protein receptor, and melatonin down-regulated the mRNA expression of hallmarks of chondrocytes, including parathyroid hormone-related protein. PCR array showed that the effect of melatonin on chondrocyte hypertrophic differentiation was accompanied by the up-regulation of multiple target genes of the canonical Wnt signaling pathway, and this effect was blocked by XAV-939.
\end{abstract}

\footnotetext{
*Correspondence: zhanglm36@mail.sysu.edu.cn; ronglm@mail.sysu.edu.cn

†Xuan Wang, Tianwei He and Lei He have contributed equally to this work

1 Department of Spine Surgery, The Third Affiliated Hospital of Sun Yat-

Sen University, Guangzhou, People's Republic of China

Full list of author information is available at the end of the article
} permits use, sharing, adaptation, distribution and reproduction in any medium or format, as long as you give appropriate credit to the original author(s) and the source, provide a link to the Creative Commons licence, and indicate if changes were made. The images or other third party material in this article are included in the article's Creative Commons licence, unless indicated otherwise in a credit line to the material. If material is not included in the article's Creative Commons licence and your intended use is not permitted by statutory regulation or exceeds the permitted use, you will need to obtain permission directly from the copyright holder. To view a copy of this licence, visit http://creativecommons.org/licenses/by/4.0/. The Creative Commons Public Domain Dedication waiver (http://creativeco mmons.org/publicdomain/zero/1.0/) applies to the data made available in this article, unless otherwise stated in a credit line to the data. 
Conclusions: The current findings demonstrate that melatonin enhances the hypertrophic differentiation of MSC-derived chondrocytes through the Wnt signaling pathway. Our findings add evidence to the role of melatonin in promoting bone development and highlight the positive effects of melatonin on terminal differentiation of chondrocytes.

Keywords: Melatonin, Mesenchymal stem cells, Chondrocyte hypertrophy, Wnt/ß-catenin

\section{Introduction}

Endochondral ossification (EO), one of the main processes in skeletal development in vertebrates, involves the progressive replacement of cartilaginous tissues by bony tissues for normal bone architecture formation [1, 2]. Mesenchymal stem cells (MSCs), the progenitors of chondrocytes, undergo a series of steps including proliferation, pre-hypertrophy and hypertrophy during $\mathrm{EO}$ for cell maturation and skeletal morphogenesis. Longitudinal bone growth occurs at the growth plate, an organized cartilaginous structure in the metaphysis [3]. The growth plate is subdivided into three structurally and functionally independent zones: the resting zone, which contains round chondrocytes; the proliferative zone, which contains flattened chondrocytes; and the hypertrophic zone, which contains enlarged chondrocytes. These zones are spatially located from both ends to the middle along the vertical axis of the long bone $[4,5]$. The hypertrophic zone serves as a signal-transducing center, in which several cell signaling pathways cross-talk with each other for the precise regulation of chondrocyte hypertrophic differentiation [5]. Chondrocyte hypertrophy contributes more substantially to bone growth rate than chondrocyte proliferation through promoting enlargement of cell volume [6, 7]. Moreover, hypertrophic chondrocytes act as "intermediators" in the turnover of cartilage to bone. Therefore, chondrocyte hypertrophic differentiation has been highlighted as the pivotal stage in EO.

Hypertrophy, an irreversible stage of chondrocyte terminal differentiation, is controlled by several signaling pathways, including the $\mathrm{Wnt} / \beta$-catenin signaling pathway [8-10]. The canonical Wnt/ $\beta$-catenin pathway orchestrates chondrocyte hypertrophy by the translocation of $\beta$-catenin into the nucleus and $\beta$-catenin binding with T cell-specific factor (TCF) or lymphoid enhancer binding protein (LEF) [11], leading to activation of the hypertrophy-related RUNX2 gene in the nucleus [12]. However, the concrete molecular framework for chondrocyte hypertrophy remains unclear.

Melatonin, an amine hormone, is mainly secreted by the pineal gland in mammals, especially in dark environments. Melatonin elicits a variety of biological functions via membrane and nuclear receptors and plays vital roles in the regulation of many pathophysiological processes [13] such as clock rhythm [14, 15], immune response [16,
17], cellular senescence [18, 19], and bone development $[20,21]$. Several studies have shown that melatonin also participates in chondrocyte differentiation and maintenance. Our previous data showed that melatonin at a lower concentration (nanomolar level) promotes the differentiation of MSCs into chondrocytes [22]. Pei et al. reported that treatment of porcine joint chondrocytes with a lower concentration's melatonin enhances the synthesis of matrix, while a higher concentration's melatonin resulted in down-regulation of cartilage gene expression [23]. Zhong ZM et al. also showed that melatonin at a high concentration (micromolar level) inhibits the proliferation and differentiation of chondrocytes in the growth plate of the vertebral body in rats [24]. These results indicate that high concentrations of melatonin may have deleterious effects on the differentiation of chondrocytes; however, melatonin at a moderate concentration may be beneficial to chondrocyte differentiation and maintenance. Although studies have shown that melatonin participates in chondrocyte differentiation, its effect on hypertrophic differentiation of chondrocytes is unknown.

In the present study, we evaluated the effect of melatonin at a moderate concentration $(100 \mathrm{nM})$ on human bone marrow mesenchymal stem cells (BMSCs) and C3H10T1/2-derived chondrocytes and further analyzed the effect of melatonin on EO. Our study aim is to provide insights into understanding skeletal development and the potential use of melatonin as a therapeutic drug for cartilage disorders and cartilage development-related diseases.

\section{Materials and methods \\ Cell culture and reagents}

This study was approved by the ethics committee of Sun Yat-Sen University, and informed consent was obtained from all the individuals included in this study. Bone marrow samples were obtained from five human volunteers (mean age: 25 years, range: $18-30$ years). MSCs were cultured by the whole bone marrow culture method [25], which fulfills the criteria proposed by the International Society for Cellular Therapy (ISCT) [26] (see Additional file 1). We used the murine mesenchymal stem cell line C3H10T1/2 (Cell Bank of the Chinese Academy of Science, Shanghai, China) in some experiments to eliminate the influence of MSC heterogeneity and acquire more 
solid information. The cell lines were cultured in $25 \mathrm{~cm}^{2}$ flasks containing $5 \mathrm{ml}$ low-glucose Dulbecco's modified Eagle's medium (DMEM) with $10 \%$ fetal bovine serum (FBS) at $37{ }^{\circ} \mathrm{C}$ with $5 \% \mathrm{CO}_{2}$. The growth medium was changed every three days. For cell passage, the cells were digested with trypsin at $80 \%$ confluence and then subcultured in flasks. After monolayer expansion, cells from passage 3-6 were selected for experiments.

In some of these experiments, the $\beta$-catenin antagonist XAV-939 $(10 \mu \mathrm{M})$ (Selleckchem, USA) was used to block the Wnt/ $\beta$-catenin signaling pathway and the agonist CHIR-90021 (5 $\mu \mathrm{M})$ (Selleckchem, USA).

\section{Chondrogenic and hypertrophic differentiation}

A high-density micromass culture system was used for the chondrogenic differentiation of MSCs and C3H10T1/2 cells, as previously described [22, 25]. The cells were trypsinized, washed with PBS, and resuspended at $2 \times 10^{7}$ cells $/ \mathrm{mL}$ in chemically defined chondrogenic medium consisting of high-glucose DMEM supplemented with $10 \mathrm{ng} / \mathrm{mL}$ recombinant human transforming growth factor- $\beta 3$ (TGF- $\beta 3$; Peprotech, USA), $100 \mathrm{nM}$ dexamethasone (Sigma, USA), $50 \mu \mathrm{g} / \mathrm{mL}$ ascorbic acid 2-phosphate (Sigma, USA), $1 \mathrm{mM}$ sodium pyruvate (Sigma, USA), $40 \mu \mathrm{g} / \mathrm{mL}$ proline (Sigma, USA), and ITS + Universal Culture Supplement Premix (Corning, USA; final concentrations: $6.25 \mu \mathrm{g} / \mathrm{mL}$ bovine insulin, $6.25 \mu \mathrm{g} / \mathrm{mL}$ transferrin, $6.25 \mu \mathrm{g} / \mathrm{mL}$ selenous acid, $5.33 \mu \mathrm{g} / \mathrm{mL}$ linoleic acid, and $1.25 \mathrm{mg} / \mathrm{mL}$ bovine serum albumin). The cell suspension $(15 \mu \mathrm{L})$ was carefully placed in each well of a 24-well plate. Cells were cultured in a $37^{\circ} \mathrm{C}$ incubator for $2 \mathrm{~h}$, and then, $500 \mu \mathrm{L}$ of chondrogenic medium was slowly added along the wall of the well. The cell aggregates were cultured in chondrogenic medium for two weeks, and the medium was changed every other day. The medium was changed to hypertrophicenhancing medium by the following steps: withdrawal of TGF- $\beta$ from the chondrogenic medium, addition of $1 \mathrm{nM}$ triiodothyronine (T3) (Sigma, USA), reduction of dexamethasone to $1 \mathrm{nM}$, and addition of vehicle or $100 \mathrm{nM}$ melatonin (Sigma, USA). We confirmed that melatonin at $100 \mathrm{nM}$ had no deleterious effects on MSCs (see Additional files 2-4). The induced hypertrophic cartilage tissues were harvested after 1-3 weeks. CHIR99021 a Wnt signaling agonist was used to activiate the $\mathrm{Wnt} / \beta$-catenin signaling pathway for determining the effect of Wnt on chondrocytes hypertrophy (see Additional files 5, 6).

\section{Reverse transcription and real-time polymerase chain reaction (RT-PCR) analysis}

Total RNA was isolated from the aggregates using the total RNA Kit (Omega Bio-Tec, USA) following the manufacturer's protocol. Total RNA (500 ng) was converted to cDNA using the reverse transcription kit (TaKaRa, JAPAN). All RT-PCRs were performed on a Roche 480 Real-Time PCR Detection System (Roche Diagnostics) in $20 \mu \mathrm{l}$ reaction volume containing $10 \mu \mathrm{l}$ of SYBR Green I Master Mix (Roche Diagnostics), $2 \mu \mathrm{l}$ of $10 \mathrm{mM}$ sense or antisense primer, and $6 \mu \mathrm{l}$ of RNAse-free water. The expressions of the following genes were examined: type $\mathrm{X}$ collagen (COL10A1), alkaline phosphatase (ALP), runtrelated transcription factor 2 (RUNX2), Indian hedgehog $(\mathrm{IHH})$, parathyroid hormone-related protein receptor (PTHrP-R), and parathyroid hormone-related protein (PTHrP) mRNAs. Glyceraldehyde-3-phosphate dehydrogenase (GAPDH) mRNA was used for normalization of gene expression. The PCR reaction conditions were as follows: $1 \mathrm{~min}$ at $95{ }^{\circ} \mathrm{C}$, followed by 39 amplification cycles of $15 \mathrm{~s}$ at $95{ }^{\circ} \mathrm{C}, 15 \mathrm{~s}$ at $60^{\circ} \mathrm{C}$, and $20 \mathrm{~s}$ at $72{ }^{\circ} \mathrm{C}$. After the last cycle, a melt curve was generated. The $\mathrm{Ct}$ value of GAPDH mRNA was subtracted from the $\mathrm{Ct}$ value of the gene of interest $(\Delta \mathrm{Ct})$. The average $\Delta \mathrm{Ct}$ value of the triplicate reactions was determined. MSCs cultured in the pellet culture system were used as controls. The relative expression level for each gene was expressed as fold change by the $2^{-\Delta \Delta \mathrm{CT}}$ method.

\section{PCR array}

Amplified cDNA was diluted with nuclease-free water and added to the $\mathrm{RT}^{2}$ qPCR SYBR green Master Mix (Roche Diagnostics). Next, $25 \mu \mathrm{l}$ of the experimental cocktail was added to each well of the Wnt signaling pathway PCR array (SA Biosciences, Frederick MD, USA). PCR amplification was performed using RT-PCR analyses as described above. Data were analyzed using the $2^{-\Delta \Delta C T}$ method and presented as fold change in the target gene normalized to the mean of endogenous housekeeping genes (GAPDH).

\section{Western blotting}

Cell and tissue lysates were lysed using RIPA lysis buffer (Beyotime, China) supplemented with the Halt ${ }^{\mathrm{TM}}$ Protease and phosphatase inhibitor cocktail (Thermo, USA). Samples were separated by electrophoresis on $8 \%$ SDSPAGE gels and transferred onto PVDF membranes (Millipore, USA). The membranes were blocked with 5\% non-fat milk, followed by incubation with primary antibodies targeting the following proteins, according to the manufacturer's instructions: TCF1/TCF7, H3, and Actin (Cell Signaling Technology, China). Membranes were then incubated with the appropriate secondary antibodies (Cell Signaling Technology) according to the manufacturer's instructions. Protein bands were developed and analyzed using an automatic chemiluminescence system (Tanon, China), and the intensity of the bands (pixels/ 
band) was determined using ImageJ software as arbitrary optical density units.

\section{Histology and immunohistochemistry}

The cartilage aggregates were fixed in $10 \%$ formaldehyde solution for $24 \mathrm{~h}$, followed by dehydration in an ethanol gradient and embedding in paraffin. The paraffin blocks were cut by a pathologic microtome section processor into sections approximately 3-5 $\mu \mathrm{m}$ thick, and the sections were carefully placed on glass slides. Toluidine blue staining was used to assess proteoglycan levels. Briefly, the sections were dewaxed with xylene and rehydrated with an alcohol gradient; the sections were then exposed to toluidine blue solution for $15 \mathrm{~min}$ and then immersed in acetone for $3 \mathrm{~min}$. Immunohistochemistry was performed to evaluate the expressions of collagen type II (Col-II) and collagen type X (Col$\mathrm{X}$ ) using the Histostain-Plus kit (ZSGB-BIO, Beijing, China). After dewaxing and rehydration, tissue sections were treated with pepsin at $37^{\circ} \mathrm{C}$ for $10 \mathrm{~min}$, incubated with peroxidase-blocking solution for $10 \mathrm{~min}$, and blocked with $5 \%$ bovine serum albumin for $30 \mathrm{~min}$ at room temperature. The sections were then incubated with the following primary antibodies overnight at $4{ }^{\circ} \mathrm{C}$ : mouse anti-human Col-X monoclonal antibodies (Abcam, USA) diluted at 1:2000 and rabbit antihuman Col-II polyclonal antibodies (Abzoom Biolabs, USA) diluted at 1:500. Detection was conducted with a DAB Horseradish Peroxidase Color Development Kit (ZSGB-BIO, Beijing, China) according to the manufacturer's protocol. Hematoxylin served as a counterstain for the nucleus. After dehydration in alcohol and clearance in xylene, the sections were mounted and photographed with a microscope (Leica, Germany).

\section{Immunofluorescence}

The cells were washed with PBS twice, fixed in $4 \%$ paraformaldehyde at room temperature for $15 \mathrm{~min}$, and washed with PBS twice. The cells were then incubated with primary antibodies against MT1, MT2, or $\beta$-actin (Abcam, USA) according to the manufacturer's instructions. The cells were washed and then incubated with species-matched secondary antibodies (Abcam, USA) labeled with Alexa Fluor 488 (Life Science, USA) diluted at 1:500 in 1\% BSA according to the manufacturer's instructions. The nuclei were labeled with Hoechst 33,342 (Beyotime Biotechnology, Beijing, China).

\section{Statistical analysis}

All experiments were performed at least three times. Statistical analysis was performed using one-way ANOVA followed by $t$ test with the SPSS version 20.0 software. $P<0 \quad 0.05$ was considered statistically significant.

\section{Results \\ Melatonin promotes hypertrophic differentiation of MSC-derived chondrocytes}

Hypertrophy contributes to an increase in the volume of an organ or tissue based on the enlargement of component cells. Therefore, to determine the effect of melatonin on hypertrophic chondrocytes, we examined the effect of melatonin on both the volume and weight of hypertrophic BMSC-derived chondrocytes. We induced hypertrophy for 1 week and 3 weeks and found that the melatonin-treated chondrocyte aggregates were much larger in size than those in the control group (Fig. 1a). The aggregates were globoids, and the volumes of aggregates were calculated by measuring the diameter; the dry weight of aggregates was measured with a precision electronic scale. Melatonin remarkably increased both the volume and weight of hypertrophic differentiated BMSC-derived chondrocytes (Fig. 1d, e). Alcian blue and toluidine blue staining were performed to reveal morphological details of single chondrocytes, and chondrocytes in the melatonin treatment group were much larger in size than that without melatonin treatment (Fig. 1b, c). The quantitative results and statistical analyses of chondrocyte diameter and volume are shown in Fig. 1f, g.

\section{Melatonin promotes hypertrophic gene expression} in the chondrogenesis of BMSCs and $\mathrm{C} 3 \mathrm{H} 10 \mathrm{~T} 1 / 2$ cells

Chondrocyte hypertrophy is characterized by the up-regulation of COL10A1, IHH, PTHrP-R, RUNX2, and ALP and the down-regulation of PTHrP. We therefore examined the mRNA expression of these factors at different time points during hypertrophic differentiation (Fig. 2af). The mRNA levels of all factors, except PTHrP mRNA, were significantly increased in the melatonin treatment group compared with the group without melatonin treatment. We performed a similar assay in C3H10T1/2 cells, and similar results were observed in C3H10T1/2 cell chondrogenesis (Fig. 2g-j).

Collagen remodeling, in which Col-II level decreases and Col-X level increases, is a characteristic event during hypertrophic differentiation. Immunohistochemistry of aggregates after hypertrophy differentiation showed that Col-II expression level decreased and Col-X expression level increased in the presence of melatonin (Fig. 3a, d). Integral optical density analysis was performed and demonstrated the positive effect of melatonin on BMSCderived chondrocyte hypertrophic biomarker expression (Fig. 3b, c, e, f). 
A

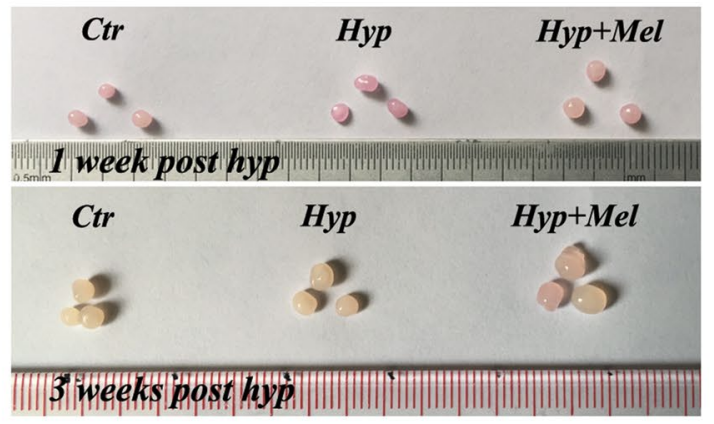

B

Ctr

Hyp

Hyp+Mel

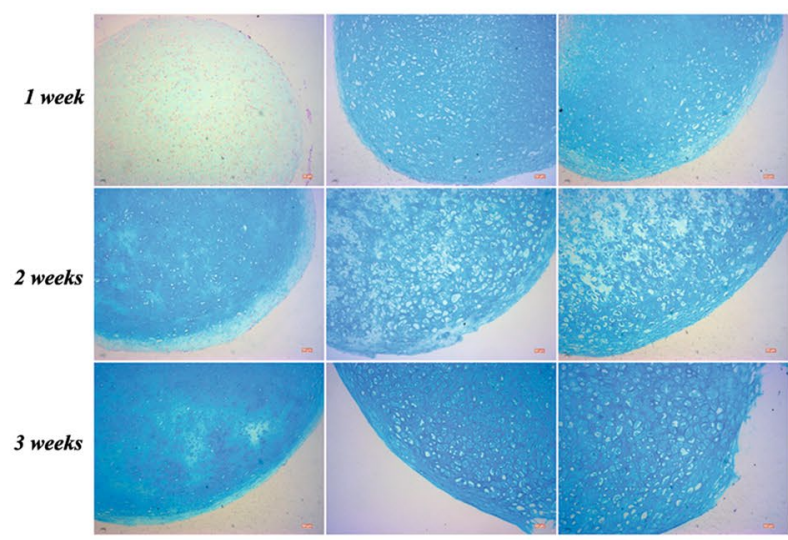

C Ctr

Hyp

Hyp+Mel

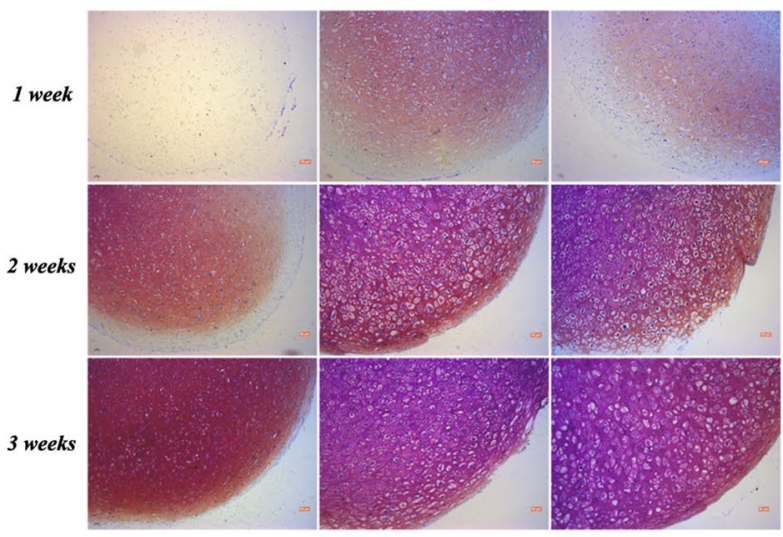

D

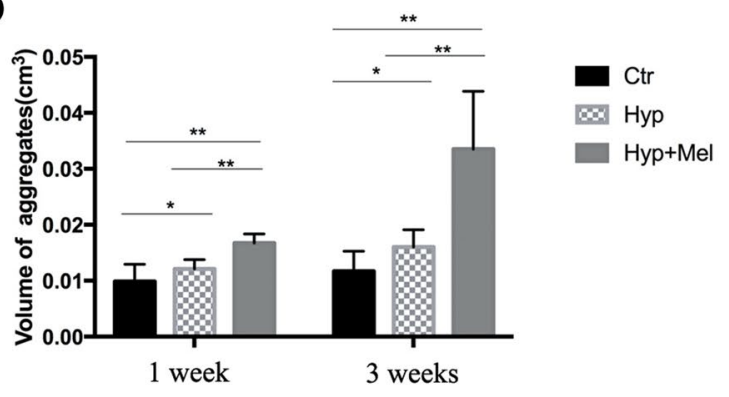

$\mathrm{E}$

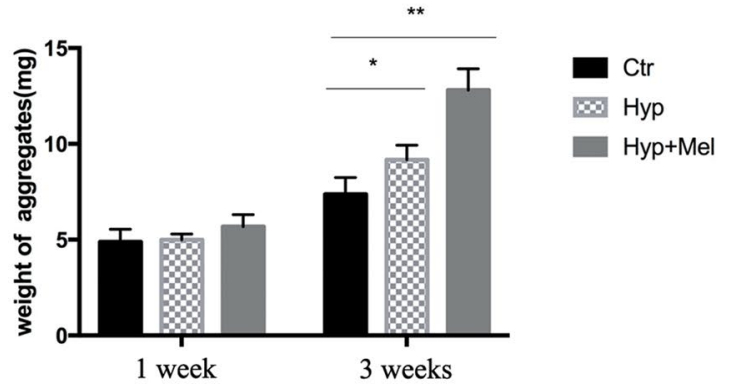

F

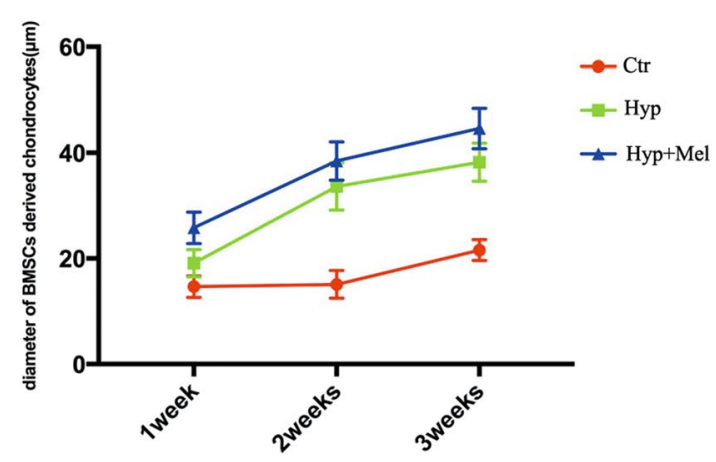

G

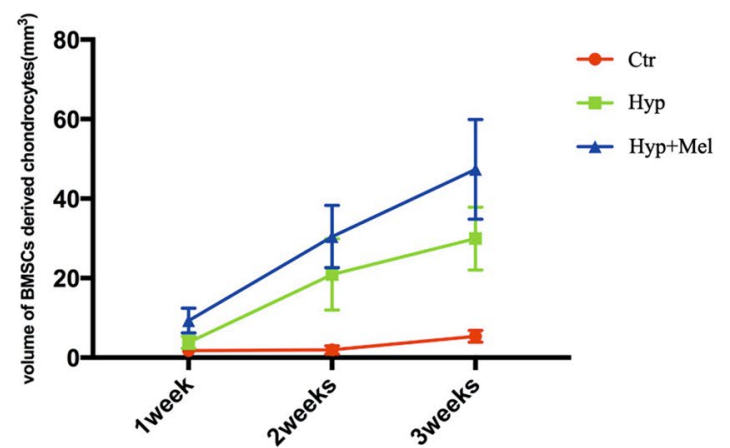

Fig. 1 Melatonin promotes hypertrophic differentiation of MSC-derived chondrocytes. a Morphologic characteristics of aggregates

post-hypertrophic differentiation at week 1 and week 3. b Alcian blue staining of chondrocytes during hypertrophic differentiation at week 1, week 2, and week 3. Scale bar $=200 \mu \mathrm{m}$. c Toluidine blue staining of chondrocytes during hypertrophic differentiation at week 1, week 2, and week 3 .

Scale bar $=200 \mu \mathrm{m}$. $\mathbf{d}$ Volume of aggregates in the indicated groups at week 1 and week 3. e Weight of aggregates in the indicated groups at week 1 and week 3. f Diameter of chondrocytes in the indicated groups at week 1, week 2, and week 3. g Volume of chondrocytes in the indicated groups at week 1 , week 2 , and week 3 (volume $=4 / 3 \pi R^{3}, R=1 / 2$ diameter). ${ }^{*} P<0.05,{ }^{*} P<0.01$ 


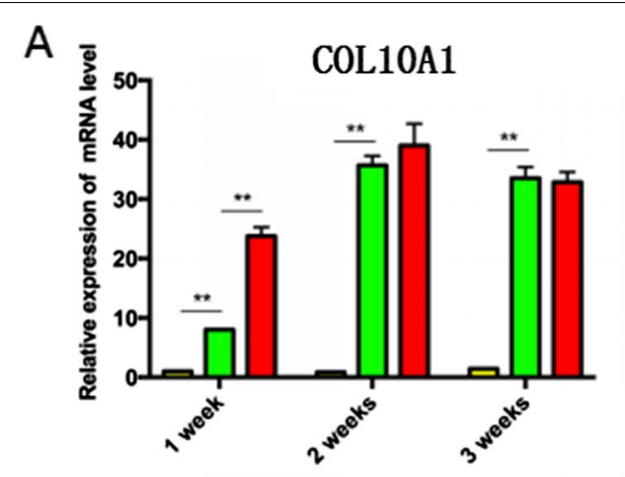

\section{C}

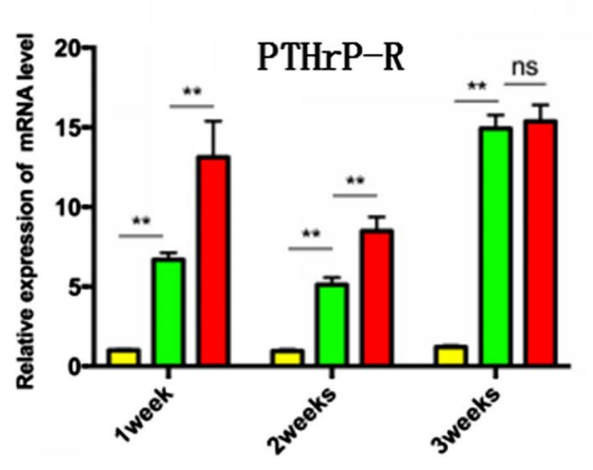

E
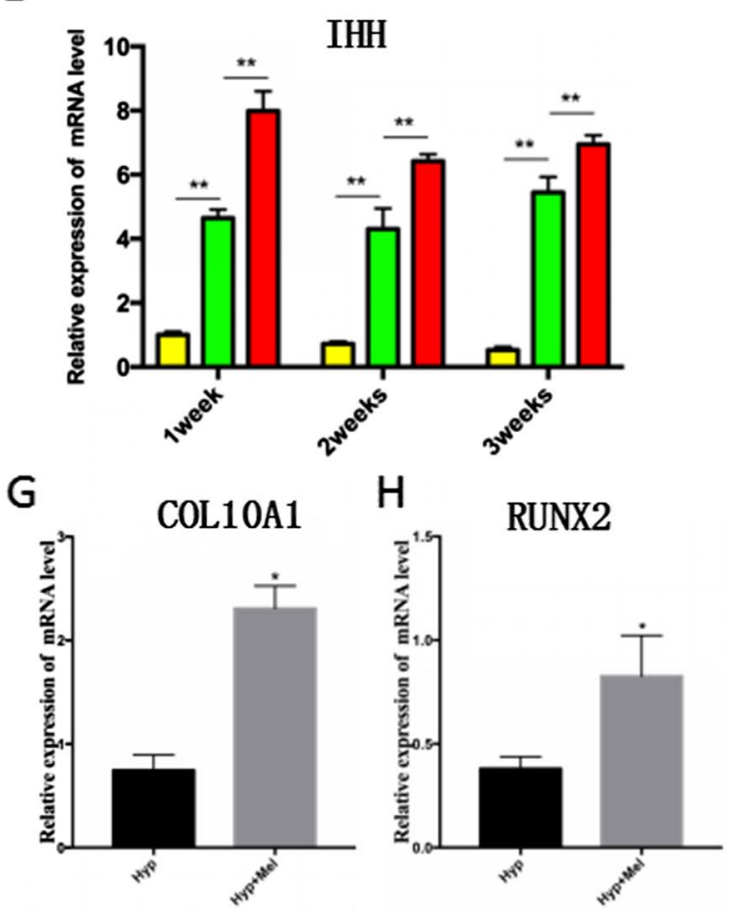

B
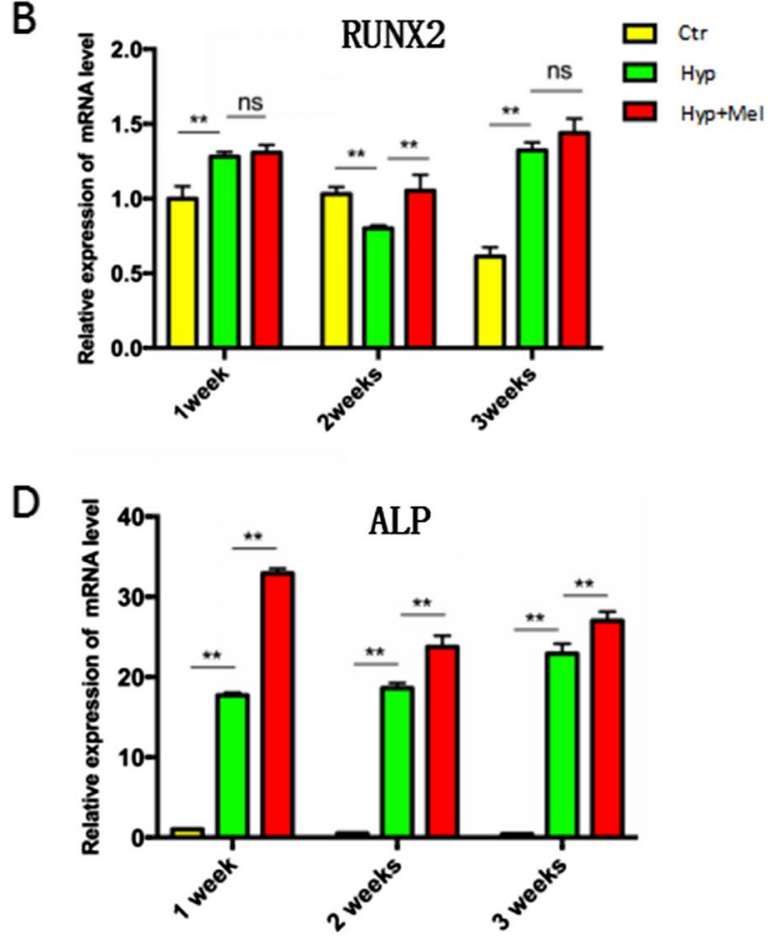

F
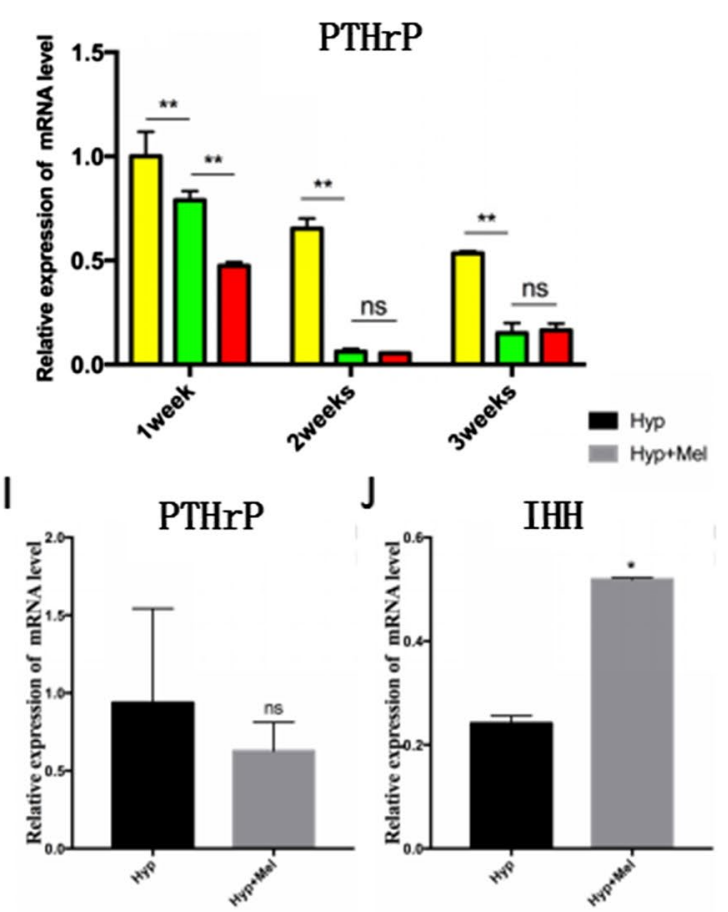

Fig. 2 Melatonin promotes hypertrophic gene expression in the stem cells derived chondrocytes. a-f The mRNA expression of collagen type X $(C O L 10 A 1)(A)$, runt-related transcription factor 2 (RUNX2) (b), parathyroid hormone-related protein receptor (PTHrP-R) (c), alkaline phosphatase $(\mathrm{ALP})(\mathbf{d})$, Indian hedgehog $(\mathrm{IHH})(\mathbf{e})$, and parathyroid hormone-related protein (PTHrP) (f) in BMSC-derived chondrocytes treated as indicated. $\mathbf{g}-\mathbf{j}$ The mRNA expression of COL10A1 (g), RUNX2 (h), PTHrP (i), and IHH (j) in C3H10T1/2 -derived chondrocytes. Gene expressions were normalized to GAPDH mRNA. * $P<0.05$; ${ }^{*} P<0.001$; ns, not significant 


\section{(See figure on next page.)}

Fig. 3 Melatonin decreases collagen-II expression and induces collagen-X expression during hypertrophy. a Immunohistochemical staining of Col-II in aggregates after hypertrophy differentiation for 3 weeks. Scale bar $=200 \mu \mathrm{m}$. b Gray value of Col-Il staining in induced cartilage tissues. c Gray value for Col-II staining in a single chondrocyte. $\mathbf{d}$ Immunohistochemical staining of Col-X in aggregates after hypertrophy differentiation for 3 weeks. Scale bar $=200 \mu \mathrm{m}$. e Gray value of Col-X staining in induced cartilage tissues. $\mathbf{f}$ Gray value for Col-X staining in a single chondrocyte. ${ }^{*} P<0.05,{ }^{* *} P<0.01$

\section{Melatonin membrane receptor inhibitor blocks melatonin-mediated hypertrophic differentiation}

To investigate whether the effect of melatonin on chondrocyte hypertrophy is mediated by membrane receptors, we examined the expressions of the melatonin membrane receptors MT1 and MT2 in C3H10T1/2 cells. Representative immunofluorescence images are presented in Fig. 4a. Furthermore, the mRNA levels of hypertrophic genes including COL10A1, RUNX2, IHH, and PTHrP-R were reduced after treatment with luzindol (a blocker of the melatonin receptor) in melatonin-mediated hypertrophic differentiation (Fig. 4b-e). These data demonstrated that melatonin-mediated hypertrophic differentiation is mediated via melatonin membrane receptors.

\section{Melatonin activates Wnt-target genes during hypertrophic differentiation of BMSC-derived chondrocytes}

To elucidate the molecular mechanism underlying melatonin-mediated hypertrophic differentiation, we conducted a qRT-PCR array analysis after melatonin treatment for 1,3 , and 5 days with or without hypertrophic inducement. We found that the expressions of multiple target genes of the Wnt/ $\beta$-catenin signaling pathway were elevated after melatonin treatment (Fig. 5a, b), especially in the melatonin treatment group at day 5 . TCF/LEF, a crucial transcription factor of the Wnt/ $\beta$ catenin signaling pathway, was up-regulated at both the mRNA level and protein level during hypertrophic differentiation in the presence of melatonin, indicating that melatonin-mediated hypertrophic differentiation might be facilitated through Wnt/ $\beta$-catenin-related genes (Fig. 5c, d).

\section{Melatonin promotes the nuclear translocation of $\beta$-catenin in $\mathrm{C} 3 \mathrm{H} 10 \mathrm{~T} 1 / 2$ cells}

$\beta$-catenin is a crucial protein that translocates from the cytoplasm into the nucleus when Wnt signaling is activated. Immunofluorescence staining of $\beta$-catenin in C3H10T1/2 cells stimulated by melatonin is shown in Fig. 6a. Nuclear accumulation of fluorescence was observed in the melatonin group and the group treated with CHIR-90021, an agonist of the Wnt pathway. Western blot revealed that the nuclear $\beta$-catenin level was up-regulated, while the cytoplasmic $\beta$-catenin level was down-regulated after melatonin stimulation, and these changes were reversed by XAV-939, an inhibitor of the Wnt/ $\beta$-catenin signaling pathway (Fig. 6b-e).

\section{Melatonin-mediated hypertrophic differentiation through Wnt/ $\beta$-catenin signaling}

Our data revealed that melatonin promoted nuclear translocation of $\beta$-catenin and activated Wnt/ $\beta$ catenin pathway target gene expression. We next examined whether these events are related to the hypertrophic differentiation of chondrocytes. We next examined hypertrophic characteristics of the chondrocytes treated with melatonin after modulation of Wnt/ $\beta$-catenin signaling using XAV-939. The results showed that the melatonin-enhanced expression of COL-X was partially reversed by XAV-939 (Fig. 7a). IOD analysis is shown in Fig. 7b. Gene expressions of RUNX2, COL10A1, and IHH were also decreased in melatonin-induced hypertrophic chondrocytes treated with XAV-939 (Fig. 7c-e).

\section{Discussion}

Our previous studies of melatonin orchestrating BMSC chondrogenesis showed that hypertrophy-related genes in the melatonin treatment group were significantly increased compared with those in the control group at a later differentiation stage [22]. In this study, we identified melatonin as a promoter of hypertrophy differentiation of MSC-derived chondrocytes. Our data revealed that melatonin promotes MSC-derived chondrocyte hypertrophic differentiation via melatonin membrane receptors, followed by the activation of the Wnt/ $\beta$-catenin signaling pathway.

Intramembranous ossification and endochondral ossification are two essential processes for bone formation and contribute to skeletal architecture and bone building [27]. Intramembranous ossification is responsible for the rudimentary development of cranial bones and also plays a role in bone fracture healing, in which MSCs directly develop into osteoblasts without cartilage participation. Unlike during intramembranous bone formation, in EO, cartilage acts as a transitional form. EO is responsible for the skeletal development of the trunk and limbs in vertebrates. 


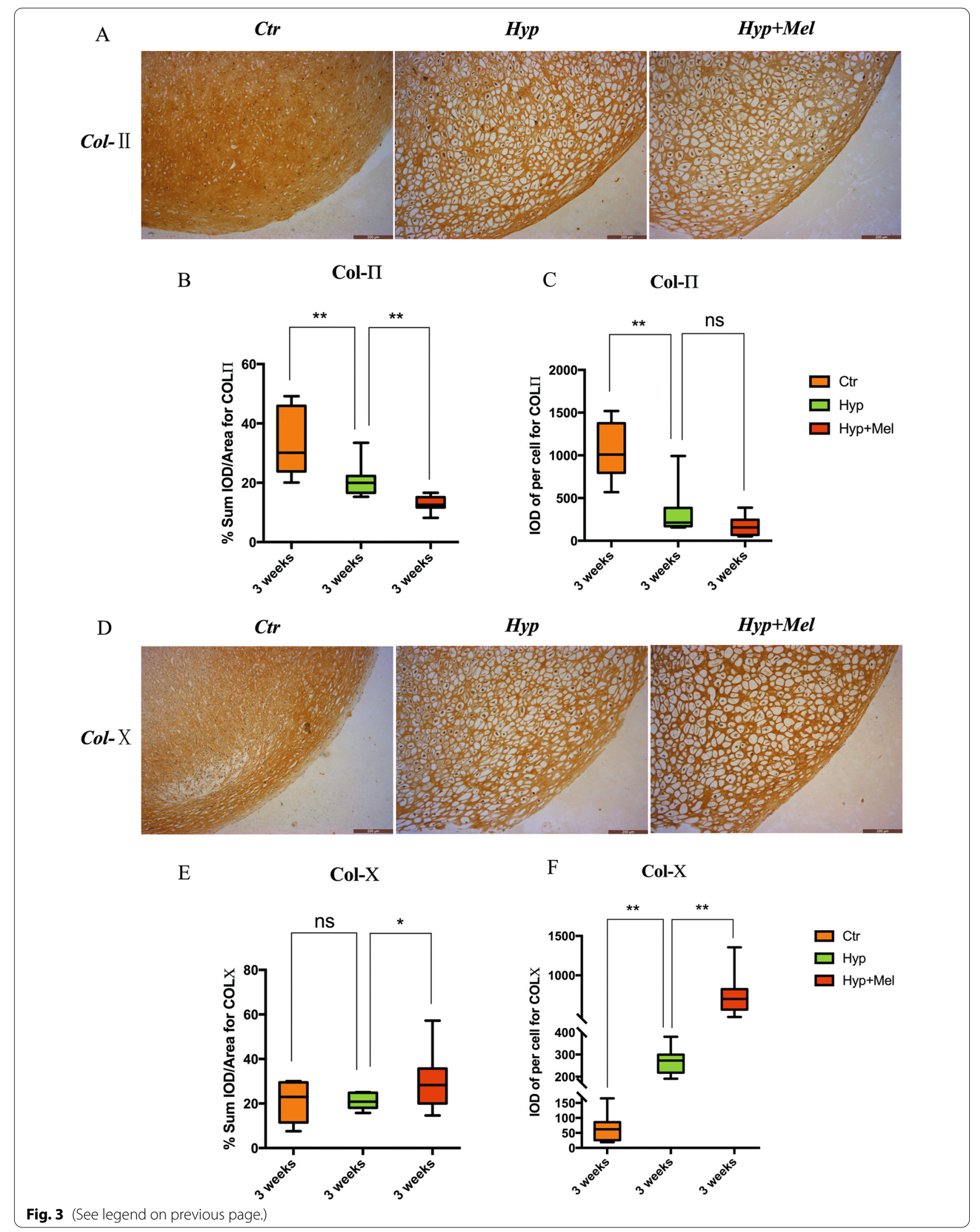


A

\section{hoechst}

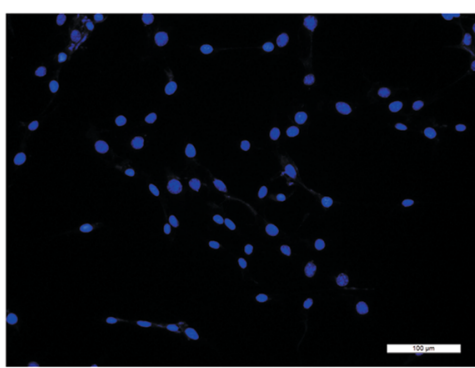

MT1

MT2

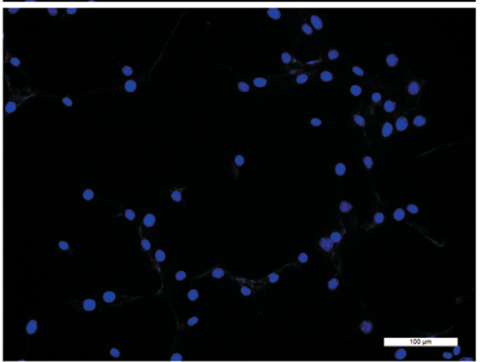

B

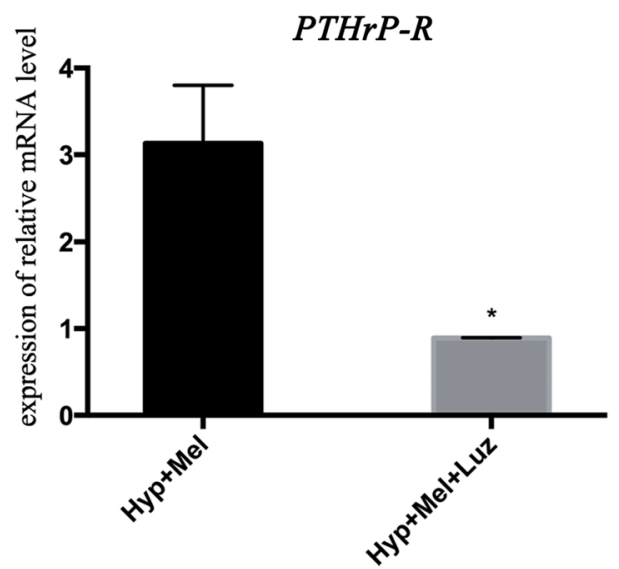

D

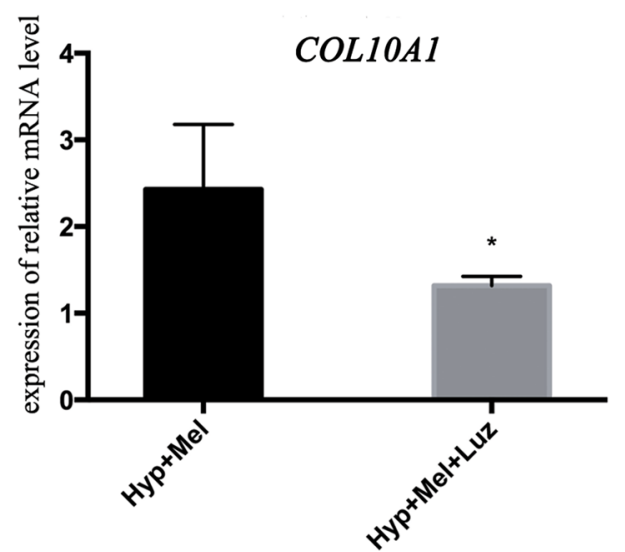

protein

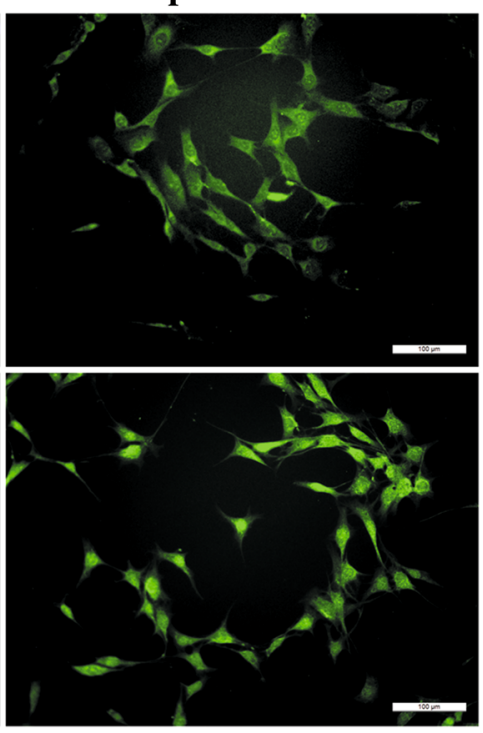

$\mathrm{C}$

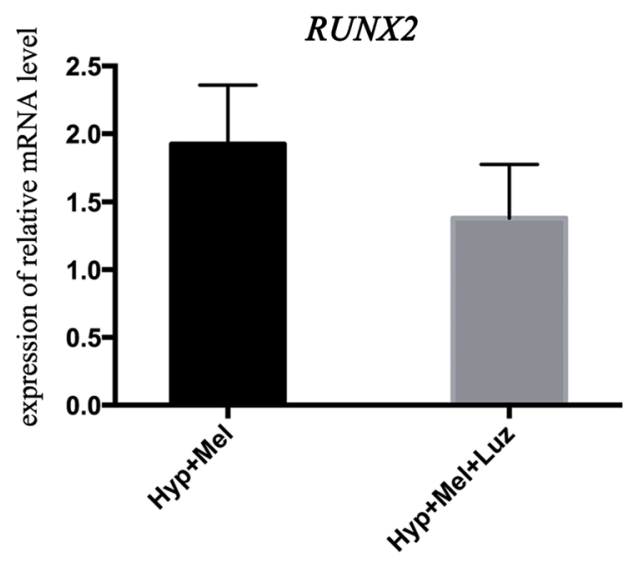

E

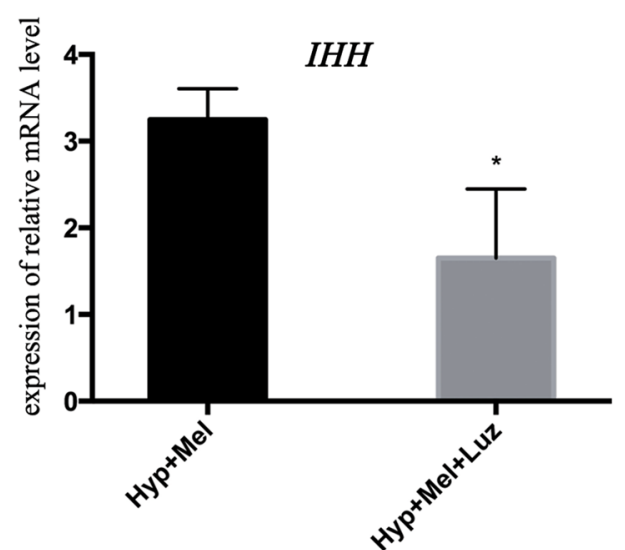

Fig. 4 Melatonin membrane receptor inhibitor blocks melatonin-mediated hypertrophy. a Immunofluorescence staining of melatonin membrane receptors MT1 and MT2 in C3H10T1/2 cells. b-e The mRNA expressions of PTHrP-R (b), RUNX2 (c), COL10A1 (d), and IHH (e) in C3H10T1/2-derived chondrocytes treated as indicated. Gene expressions were normalized to GAPDH mRNA. ${ }^{*} P<0.05$ 


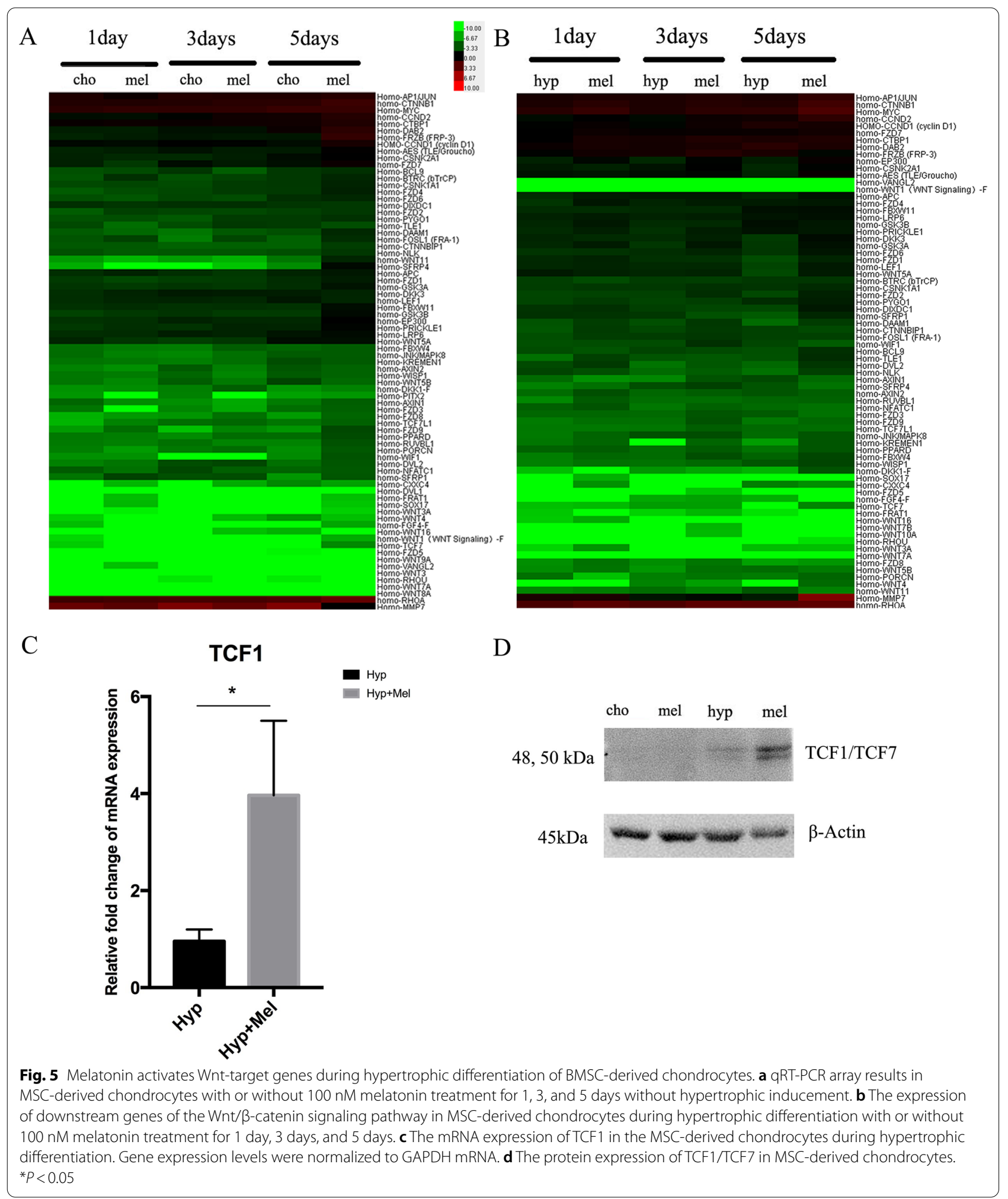

In previous studies, melatonin was found to be involved in the cell fate choice of BMSC differentiation into osteoblasts rather than adipocytes [28-30]. These findings revealed the anti-osteoporosis action of melatonin. Melatonin is also regarded as a bio-activator for bone repair because of its anti-oxygenation ability in the early stage of 

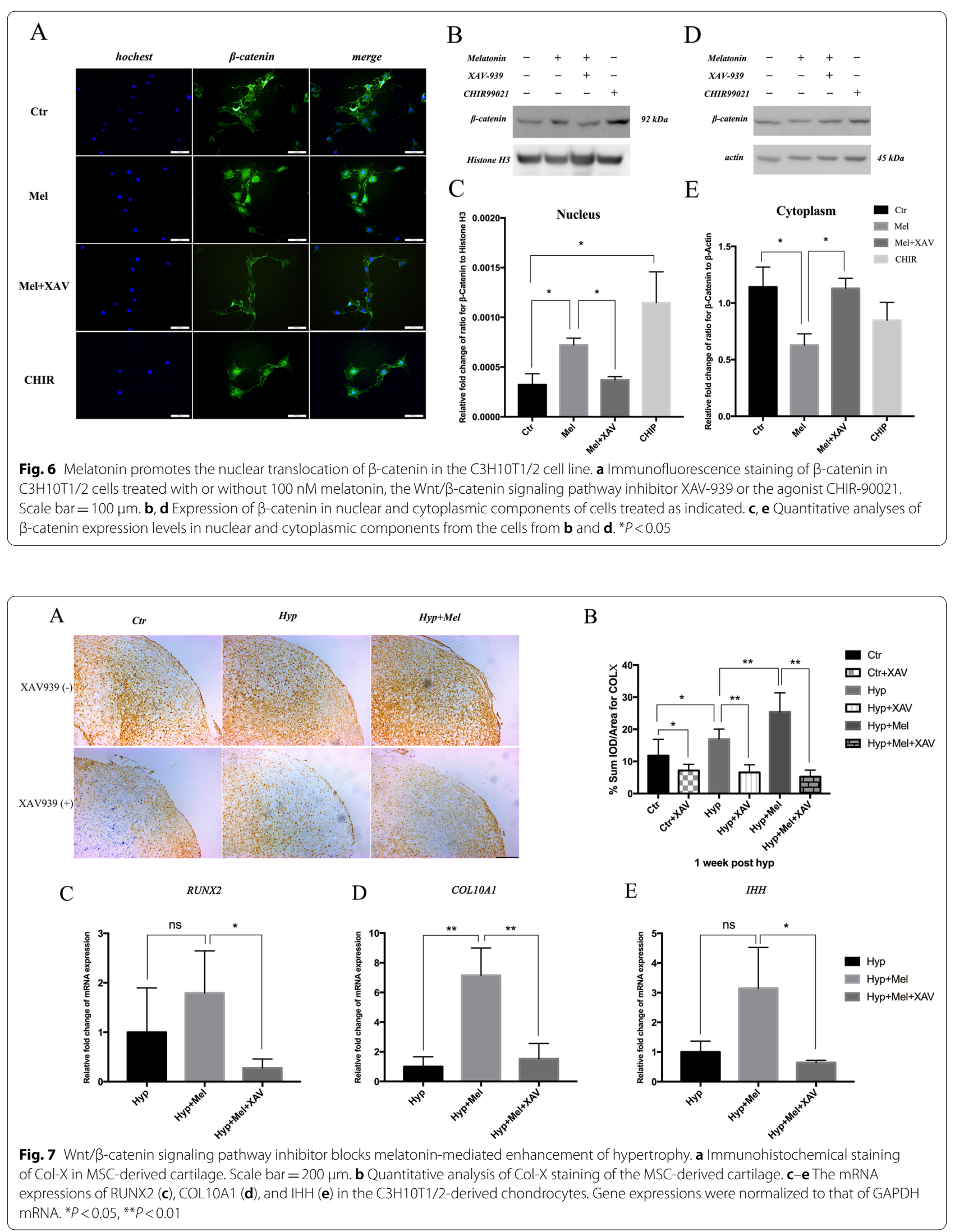
bone repair and its angiogenesis-promoting ability in the late stage of bone repair [31, 32].

Studies have shown that melatonin promoted the production of the cartilage matrix in porcine articular chondrocytes and up-regulated the chondrocyte hallmark Col-II rather than the hypertrophic biomarker Col-X [23]. Our previous study showed that melatonin enhanced the chondrogenesis of human BMSCs, partially via melatonin membrane receptors [22]. We found that melatonin up-regulated the expression of the hypertrophy-related genes COL10A1 and RUNX2 in human BMSC-derived chondrocytes in chondrogenic medium [22]. Melatonin is considered to have a protective effect on cartilage homeostasis because of its resistance against inflammation and oxidization in the maintenance of cartilaginous joints. Guo et al. reported that melatonin reduces matrix metalloproteinase production via the inhibition of Sirtuin-1-dependent NAMPT and NFAT5 signaling in chondrocytes [33]. Melatonin combined with treadmill exercise may have both preventive and synergistic effects on cartilage degeneration and is more effective in its initial phase.

Hypertrophic chondrocytes are recognized as the greatest contributors to the bone growth rate because of the expansion of cell volume in the growth plate. These cells are also excellent predictors of joint degenerative diseases, such as osteoarthritis, which is an agerelated disorder that causes the loss of cartilage in joints. Although hypertrophic chondrocytes in the growth plate share high similarities with those in degenerative joints in terms of gross morphology, these cells are not exactly the same. Cooper et al. reported that chondrocytes in the growth plate undergo three phases for hypertrophic differentiation: Phase 1, true hypertrophy, is characterized by dry mass production that proportionately increases with fluid uptake; phase 2, cell swelling, is characterized by fluid uptake that increases proportionately and greater than dry mass production; and phase 3 , another true hypertrophy, is controlled by the IGF1 signaling pathway [7]. In contrast to growth plate chondrocytes, articular chondrocytes increase in volume by extracellular matrix degradation and collagen network damage, leading to hypo-osmotic swelling in the initial stage of osteoarthritis [34-37].

A previous study reported that melatonin treatment reduced the mRNA levels of hypertrophic markers such as COL10A1 and ALP in the growth plate chondrocytes [38]. Our present data, acquired from both human BMSC and C3H10T1/2 cell analysis, demonstrated that melatonin up-regulated the hallmarks of hypertrophic chondrocytes, such as COL10A1, RUNX2, and ALP. Two opposite functions of melatonin were observed, which may be from the cellular heterogeneity of different chondrocytes. Growth plate chondrocytes are composed of rest, proliferative, and hypertrophic chondrocytes, which are differentiated cells with a high level of hypertrophy markers. Therefore, melatonin treatment cannot further enhance the expression of the hypertrophic hallmarks for these mature chondrocytes. Chondrocytes from MSCs, which are cells with multi-lineage differentiation potentials, showed favorable ability for hypertrophic differentiation in a micromass culture system [39], and therefore, our results provided completely different information in effect of melatonin on the chondrocytes differentiation. The IHH/PTHrP negative feedback loop acts as a pivotal effector of EO. IHH, expressed in pre-hypertrophic chondrocytes, promotes the production of PTHrP in proliferative chondrocytes. PTHrP suppresses IHH expression by binding with PTHrP receptors, which are expressed on the membrane of hypertrophic chondrocytes, leading to an outcome that favors chondrocyte proliferation over hypertrophic differentiation. Our results showed that melatonin enhanced IHH and PTHrP-R expression and suppressed $\mathrm{PTHrP}$ in human BMSC-derived chondrocytes. Collectively, our current results indicate that melatonin acts as a vital promoter of EO by regulating chondrocyte hypertrophy during MSC differentiation.

The hypertrophic differentiation of chondrocytes is regulated by many cellular pathways, and previous studies have shown that the classical Wnt pathway is involved in this process. The Wnt pathway is divided into classical and non-classical Wnt pathways according to whether the downstream pathways require $\beta$-catenin parameters [40-42]. Both classical and non-classical Wnt pathways play an important role in the development of bone and cartilage. Many Wnt proteins have been found in the cartilage growth plate [43]. Hartmann et al. found that Wnt5b/11 was expressed in pre-hypertrophic chondrocytes in chicken limb buds, while Wnt4 was not expressed in hypertrophic chondrocytes [44]. Rudnicki et al. also found that the abnormal distribution of Wnt7 led to limb chondrodysplasia in chickens [45]. Similar studies have shown that abnormalities in Wnt5a/5b hinder limb cartilage hypertrophy and differentiation [43, 44]. Notably, Wnt proteins are not expressed in resting and proliferative chondrocytes but are mainly expressed in hypertrophic and pre-hypertrophic chondrocytes [44]. These Wnt proteins primarily originate from the perichondrium and osteoblasts in the surrounding cancellous bone. In this study, after chondrocytes derived from stem cells were cultured in 3D and hypertrophy was induced by the addition of thyroxine T3, gene chip analysis showed no significant difference in the expression of Wnt5a/5b and Wnt4 proteins in these cells; however, a decrease in the gene expression of Wnt11 and 
no detecting of other Wnt genes were observed. This may be because Wnt proteins mainly originate from the perichondrium and osteoblasts around the growth plate in vivo but do not originate from chondrocytes.

XAV-939 is an inhibitor of the terminal anchor polymerase (tankyrase) that accelerates the degradation of $\beta$-catenin by stabilizing the axis inhibitor Axin, thus affecting the nuclear translocation of $\beta$-catenin and regulating the transcription of target genes downstream of the ganglion [46]. In this study, the hypertrophic effect of melatonin on cartilage was inhibited by XAV-939. Immunohistochemistry revealed that expression of Col-X was lower and the extent of staining was smaller in the melatonin + XAV939 group compared with the melatonin group. This suggests that melatonin promotes the hypertrophy of MSCderived chondrocytes by regulating the nuclear translocation of $\beta$-catenin. Western blot showed that the nuclear expression of $\beta$-catenin increased significantly and cytoplasmic $\beta$-catenin decreased after the addition of melatonin, and these events were reversed by treatment with XAV939. These findings suggested that melatonin promotes the nuclear translocation of $\beta$-catenin.

In summary, our results indicate that the molecular mechanism by which melatonin promotes hypertrophy and differentiation of MSC-derived chondrocytes involves activation of the Wnt/ $\beta$-catenin signal pathway and increasing the nuclear translocation of $\beta$-catenin.

This study had several limitations. First, we used MSCs isolated from human bone marrow, which fulfills the criteria proposed by the ISCT [26]. However, MSCs isolated according to ISCT criteria can produce heterogeneous, non-clonal cultures of stromal cells containing stem cells with different multipotential properties, committed progenitors, and differentiated cells $[47,48]$. Therefore, further studies are needed to explore whether melatonin contributes to the hypertrophic differentiation of chondrocytes derived from special subpopulations of MSCs or MSCs isolated from other tissues, such as adipose tissue, umbilical cord, and dental pulp. Second, our results demonstrating the effects of melatonin on chondrocyte terminal differentiation were derived from in vitro studies with human MSCs and the C3H10T1/2 cell line. In vivo studies are required to confirm these preliminary findings. Finally, this study demonstrates the link between melatonin and Wnt/B-catenin in hypertrophic differentiation of chondrocytes. The connection between melatonin and Wnt/ $\beta$-catenin was previously shown in osteogenesis [49] and cancer metastasis [50]. Although these studies suggest a functional relationship between melatonin and Wnt/ $\beta$-catenin that may be involved in various biological processes, the precise mechanism how melatonin activates the Wnt/ $\beta$-catenin pathway had not been explored. Therefore, further studies revealing the specific mechanism by which $\mathrm{Wnt} / \beta$-catenin is activated by melatonin are needed.

\section{Conclusions}

Our results suggest that melatonin enhances the hypertrophic differentiation of MSC-derived chondrocytes through the Wnt signaling pathway. These findings provide evidence establishing the role of melatonin in the regulation of MSC differentiation and bone development. Our results may facilitate the clinical application of melatonin in the treatment of skeletal developmental diseases.

\section{Abbreviation}

MSCs: Mesenchymal stem cells; COL10A1: Type X collagen; ALP: Alkaline phosphatase; RUNX2: Runt-related transcription factor 2; IHH: Indian hedgehog; PTHrP-R: Parathyroid hormone-related protein receptor; PTHrP: Parathyroid hormone-related protein; EO: Endochondral ossification; TCF: T cell-specific factor; LEF: Lymphoid enhancer binding protein; BMSC: Bone marrow mesenchymal stem cell; DMEM: Dulbecco's modified Eagle's medium; FBS: Fetal bovine serum; PCR: Polymerase chain reaction; TGF- $\beta 3$ : Transforming growth factor- $\beta 3$; COLX: Collagen type X; GAPDH: Glyceraldehyde-3-phosphate dehydrogenase; Col-II:Type II collagen; Col-X: Type X collagen; IOD: Integral optical density; GRT-PCR: Quantitative real-time polymerase chain reaction; TCF/LEF: T-cell factor/lymphoid enhancer factor; GPC: Growth plate chondrocyte; HBMSC: Human bone marrow mesenchymal stem cell; MMP13: Matrix metalloproteinase 13.

\section{Supplementary Information}

The online version contains supplementary material available at https://doi. org/10.1186/s13287-021-02536-x.

Additional file 1. Expression of surface markers in BMSCs. The third passage of primary isolated BMSCs was subjected to flow cytometry to investigate the expression of CD105, CD73, CD34, CD 45, and HLA. These results were representative of three independent experiments.

Additional file 2. The effect of melatonin on the viability and proliferation of BMSCs. The third passage of primary isolated BMSCs was cultured with or without melatonin treatment at different concentrations for 24 , $48 \mathrm{~h}$ and then were subjected to CCK8 assay. The absorbance at $450 \mathrm{~nm}$ was measured at each time point. The results were representative of three independent experiments, and the data were presented as mean \pm SD. Ns, no significance versus control group at different time points.

Additional file 3. Flow cytometry analysis of apoptosis with Annexin V/PI staining. The third passage of BMSCs was treated with different concentrations of melatonin for $48 \mathrm{~h}$ and then were collected to perform flow cytometry Apoptosis Assay. The percentage of apoptotic cells was showed in the histogram, presenting the early (FITC+/PI-), late (FITC+/ $\mathrm{PI}+$ ), and total apoptotic cells, respectively. These results $(\mathbf{a}-\mathbf{d})$ were representative pictures of three independent experiments. ${ }^{*} P<0.05$, ${ }^{*} P<0.01$, ns was no significance versus the corresponding control group at each apoptotic stage.

Additional file 4. Cell senescence assay with $\beta$-galactosidase staining. a The third passage of BMSCs was treated with different concentrations of melatonin for $48 \mathrm{~h}$ and then were collected to $\beta$-galactosidase staining. The senescent cells were dyed blue in each treatment group, scale 
$\mathrm{bar}=100 \mu \mathrm{m} . \mathbf{b}$ The percentage of senescent cells was calculated with Image J. ${ }^{*} P<0.05$ versus control, ${ }^{* *} P<0.01$ versus control.

Additional file 5. The effect of CHIR99021 on the hypertrophic differentiation of BMSCs-derived chondrocytes. The third passage BMSCs were under chondrogenic inducement for two weeks, and then hypertrophic inducement (with or without 5 MM CHIR99021) for one week, the cells were collected and collected to perform RT-PCR analysis to investigate the expression of collagen type X (COL10A1) (a), alkaline phosphatase (ALP) (b), runt-related transcription factor 2 (RUNX2) (c), and Indian hedgehog $(\mathrm{IHH})(\mathbf{d})$. Relative gene expression levels were calculated by using the

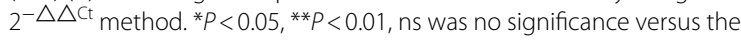
corresponding control group.

Additional file 6. Supplementary methods and materials.

\section{Acknowledgements}

We are grateful to all the clinical investigators and volunteers included in the study.

\section{Authors' contributions}

$L M R, L M Z$, and XW contributed to conception and design and drafting of the article; XW and TWH were involved in data analysis and interpretation and manuscript writing; PGX and MP contributed to provision of study materials and MSC quality control; XW, TWH, LH, BY, and ZYL were involved in collection and assembly of data; and LMR and LMZ obtained funding. All authors read and approved the final manuscript.

\section{Funding}

This study was supported by National Natural Science Foundation of China (No. 81972111, No. 81772398 and No. 81301524) and the Fundamental Research Funds for the Central Universities (No. 15ykpy23).

\section{Availability of data and materials}

The data sets used and analyzed during the current study are available from the corresponding author upon reasonable request.

\section{Declarations}

\section{Ethics approval and consent to participate}

The study design was approved by the Ethics Committee of The Third Affiliated Hospital of Sun Yat-sen University, Guangzhou, China. All included volunteers were informed about the nature of the study and provided written informed consent.

\section{Consent for publication}

All volunteers signed a consent form for their data to be used for research or publication.

\section{Competing interests}

The authors declare that they have no competing interests.

\section{Author details}

'Department of Spine Surgery, The Third Affiliated Hospital of Sun Yat-Sen University, Guangzhou, People's Republic of China. ${ }^{2}$ Guangdong Provincial Center for Quality Control of Minimally Invasive Spine Surgery, Guangzhou, People's Republic of China. ${ }^{3}$ Guangdong Provincial Center for Engineering and Technology Research of Minimally Invasive Spine Surgery, Guangzhou, People's Republic of China.

Received: 20 April 2021 Accepted: 5 August 2021

Published online: 21 August 2021

\section{References}

1. Kronenberg HM. Developmental regulation of the growth plate. Nature. 2003:423(6937):332-6.
2. White $A$, Wallis $G$. Endochondral ossification: a delicate balance between growth and mineralisation. Curr Biol. 2001;11(15):R589-591.

3. Mackie EJ, Tatarczuch L, Mirams M. The skeleton: a multi-functional complex organ: the growth plate chondrocyte and endochondral ossification. J Endocrinol. 2011;211(2):109-21.

4. Sun MM, Beier F. Chondrocyte hypertrophy in skeletal development, growth, and disease. Birth Defects Res C Embryo Today. 2014;102(1):74-82.

5. Long F, Ornitz DM. Development of the endochondral skeleton. Cold Spring Harb Perspect Biol. 2013;5(1):a008334.

6. Kuhn JL, DeLacey JH, Leenellett EE. Relationship between bone growth rate and hypertrophic chondrocyte volume in New Zealand white rabbits of varying ages. J Orthop Res. 1996;14(5):706-11.

7. Cooper KL, Oh S, Sung Y, Dasari RR, Kirschner MW, Tabin CJ. Multiple phases of chondrocyte enlargement underlie differences in skeletal proportions. Nature. 2013:495(7441):375-8.

8. Zhong L, Huang X, Karperien M, Post JN. The regulatory role of signaling crosstalk in hypertrophy of MSCs and human articular chondrocytes. Int J Mol Sci. 2015;16(8):19225-47.

9. Guo X, Mak KK, Taketo MM, Yang Y. The Wnt/beta-catenin pathway interacts differentially with PTHrP signaling to control chondrocyte hypertrophy and final maturation. PLoS ONE. 2009;4(6):e6067.

10. Yano F, Saito T, Ogata N, Yamazawa T, lino M, Chung UI, Kawaguchi H. beta-catenin regulates parathyroid hormone/parathyroid hormonerelated protein receptor signals and chondrocyte hypertrophy through binding to the intracellular C-terminal region of the receptor. Arthritis Rheum. 2013;65(2):429-35.

11. Yano F, Kugimiya F, Ohba S, Ikeda T, Chikuda H, Ogasawara T, Ogata N, Takato T, Nakamura K, Kawaguchi H, et al. The canonical Wnt signaling pathway promotes chondrocyte differentiation in a Sox9-dependent manner. Biochem Biophys Res Commun. 2005:333(4):1300-8.

12. Dong YF. Soung do Y, Schwarz EM, O'Keefe RJ, Drissi H: Wnt induction of chondrocyte hypertrophy through the Runx2 transcription factor. J Cell Physiol. 2006;208(1):77-86.

13. Claustrat B, Leston J. Melatonin: physiological effects in humans. Neurochirurgie. 2015;61(2-3):77-84.

14. Johnston JD, Skene DJ. 60 years of neuroendocrinology: regulation of mammalian neuroendocrine physiology and rhythms by melatonin. J Endocrinol. 2015;226(2):T187-198.

15. Arendt J. Melatonin and human rhythms. Chronobiol Int. 2006;23(1-2):21-37.

16. Vinther $\mathrm{AG}$, Claesson $\mathrm{MH}$. The influence of melatonin on the immune system and cancer. Ugeskr Laeger. 2015;177(21):V10140568.

17. Singh AK, Ghosh S, Basu P, Haldar C. Daily variation in melatonin level, antioxidant activity and general immune response of peripheral blood mononuclear cells and lymphoid tissues of Indian goat Capra hircus during summer and winter. Indian J Exp Biol. 2014;52(5):467-77.

18. Zhou L, Chen X, Liu T, Gong Y, Chen S, Pan G, Cui W, Luo ZP, Pei M, Yang $\mathrm{H}$, et al. Melatonin reverses $\mathrm{H}_{2} \mathrm{O}_{2}$-induced premature senescence in mesenchymal stem cells via the SIRT1-dependent pathway. J Pineal Res. 2015:59(2):190-205.

19. Parisotto EB, Vidal V, Garcia-Cerro S, Lantigua S, Wilhelm Filho D, Sanchez-Barcelo EJ, Martinez-Cue C, Rueda N. Chronic melatonin administration reduced oxidative damage and cellular senescence in the hippocampus of a mouse model of down syndrome. Neurochem Res. 2016;41(11):2904-13.

20. Sharan K, Lewis K, Furukawa T, Yadav VK. Regulation of bone mass through pineal-derived melatonin-MT2 receptor pathway. J Pineal Res. 2017;63(2):e12423.

21. van der Pol CW, van Roovert-Reijrink IAM, Maatjens CM, Gussekloo SWS, Kranenbarg S, Wijnen J, Pieters RPM, Schipper H, Kemp B, van den Brand H. Light-dark rhythms during incubation of broiler chicken embryos and their effects on embryonic and post hatch leg bone development. PLoS ONE. 2019;14(1):e0210886.

22. Gao W, Lin M, Liang A, Zhang L, Chen C, Liang G, Xu C, Peng Y, Chen C, Huang $D$, et al. Melatonin enhances chondrogenic differentiation of human mesenchymal stem cells. J Pineal Res. 2014;56(1):62-70.

23. Pei M, He F, Wei L, Rawson A. Melatonin enhances cartilage matrix synthesis by porcine articular chondrocytes. J Pineal Res. 2009;46(2):181-7.

24. Zhong ZM, Li T, Xu ZX, Meng TT, Zeng JH, Zheng S, Ye WB, Wu Q, Chen JT. Effect of melatonin on the proliferation and differentiation of 
chondrocytes from rat vertebral body growth plate in vitro. Int J Med Sci. 2013;10(10):1392-8.

25. Zhang L, Su P, Xu C, Yang J, Yu W, Huang D. Chondrogenic differentiation of human mesenchymal stem cells: a comparison between micromass and pellet culture systems. Biotechnol Lett. 2010;32(9):1339-46.

26. Dominici M, Le Blanc K, Mueller I, Slaper-Cortenbach I, Marini F, Krause D, Deans R, Keating A, Prockop D, Horwitz E. Minimal criteria for defining multipotent mesenchymal stromal cells. The International Society for Cellular Therapy position statement. Cytotherapy. 2006:8(4):315-7.

27. Berendsen AD, Olsen BR. Bone development. Bone. 2015;80:14-8.

28. Zhang L, Su P, Xu C, Chen C, Liang A, Du K, Peng Y, Huang D. Melatonin inhibits adipogenesis and enhances osteogenesis of human mesenchymal stem cells by suppressing PPARgamma expression and enhancing Runx2 expression. J Pineal Res. 2010;49(4):364-72.

29. Radio NM, Doctor JS, Witt-Enderby PA. Melatonin enhances alkaline phosphatase activity in differentiating human adult mesenchymal stem cells grown in osteogenic medium via MT2 melatonin receptors and the MEKJERK (1/2) signaling cascade. J Pineal Res. 2006;40(4):332-42.

30. Han Y, Kim YM, Kim HS, Lee KY. Melatonin promotes osteoblast differentiation by regulating Osterix protein stability and expression. Sci Rep. 2017;7(1):5716.

31. Calvo-Guirado JL, Ramirez-Fernandez MP, Gomez-Moreno G, MateSanchez JE, Delgado-Ruiz R, Guardia J, Lopez-Mari L, Barone A, Ortiz-Ruiz AJ, Martinez-Gonzalez JM, et al. Melatonin stimulates the growth of new bone around implants in the tibia of rabbits. J Pineal Res. 2010;49(4):356-63.

32. Halici M, Oner M, Guney A, Canoz O, Narin F, Halici C. Melatonin promotes fracture healing in the rat model. Eklem Hastalik Cerrahisi. 2010;21(3):172-7.

33. Guo JY, Li F, Wen YB, Cui HX, Guo ML, Zhang L, Zhang YF, Guo YJ, Guo YX. Melatonin inhibits Sirt1-dependent NAMPT and NFAT5 signaling in chondrocytes to attenuate osteoarthritis. Oncotarget. 2017;8(34):55967-83.

34. McArthur SD, Gardner DL. Articular cartilage fibrillation and permeability to Light Green SF dye. A method for the detection of pre-microscopic disease? J Bone Joint Surg Br. 1992;74(5):668-72.

35. Wang Z, Irianto J, Kazun S, Wang W, Knight MM. The rate of hypoosmotic challenge influences regulatory volume decrease (RVD) and mechanical properties of articular chondrocytes. Osteoarthritis Cartilage. 2015;23(2):289-99.

36. Venn M, Maroudas A. Chemical composition and swelling of normal and osteoarthrotic femoral head cartilage. I. Chemical composition. Ann Rheum Dis. 1977:36(2):121-9.

37. Watson PJ, Carpenter TA, Hall LD, Tyler JA. Cartilage swelling and loss in a spontaneous model of osteoarthritis visualized by magnetic resonance imaging. Osteoarthritis Cartilage. 1996;4(3):197-207.
38. Wang WW, Man GC, Wong JH, Ng TB, Lee KM, Ng BK, Yeung HY, Qiu Y, Cheng JC. Abnormal response of the proliferation and differentiation of growth plate chondrocytes to melatonin in adolescent idiopathic scoliosis. Int J Mol Sci. 2014;15(9):17100-14.

39. Mueller MB, Tuan RS. Functional characterization of hypertrophy in chondrogenesis of human mesenchymal stem cells. Arthritis Rheum. 2008:58(5):1377-88.

40. Nusse R. Wnt signaling in disease and in development. Cell Res. 2005;15(1):28-32.

41. Nusse R, Clevers H. Wnt/beta-catenin signaling, disease, and emerging therapeutic modalities. Cell. 2017;169(6):985-99.

42. Miller JR, Hocking AM, Brown JD, Moon RT. Mechanism and function of signal transduction by the Wnt/beta-catenin and Wnt/Ca2+ pathways. Oncogene. 1999;18(55):7860-72.

43. Yang Y, Topol L, Lee H, Wu J. Wnt5a and Wnt5b exhibit distinct activities in coordinating chondrocyte proliferation and differentiation. Development. 2003;130(5):1003-15.

44. Hartmann C, Tabin CJ. Dual roles of Wnt signaling during chondrogenesis in the chicken limb. Development. 2000;127(14):3141-59.

45. Rudnicki JA, Brown AM. Inhibition of chondrogenesis by Wnt gene expression in vivo and in vitro. Dev Biol. 1997;185(1):104-18.

46. Huang SM, Mishina YM, Liu S, Cheung A, Stegmeier F, Michaud GA, Charlat O, Wiellette E, Zhang Y, Wiessner S, et al. Tankyrase inhibition stabilizes axin and antagonizes Wnt signalling. Nature. 2009;461 (7264):614-20.

47. Squillaro T, Peluso G, Galderisi U. Clinical Trials With Mesenchymal Stem Cells: An Update. Cell Transplant. 2016;25(5):829-48.

48. Alessio N, Squillaro T, Özcan S, Di Bernardo G, Venditti M, Melone M, Peluso G, Galderisi U. Stress and stem cells: adult Muse cells tolerate extensive genotoxic stimuli better than mesenchymal stromal cells. Oncotarget. 2018;9(27):19328-41.

49. Xu L, Zhang L, Wang Z, Li C, Li S, Li L, Fan Q, Zheng L. Melatonin Suppresses Estrogen Deficiency-Induced Osteoporosis and Promotes Osteoblastogenesis by Inactivating the NLRP3 Inflammasome. Calcified Tissue Int. 2018;103(4):400-10.

50. Bu S, Wang Q, Sun J, Li X, Gu T, Lai D. Melatonin suppresses chronic restraint stress-mediated metastasis of epithelial ovarian cancer via NE/ AKT/B-catenin/SLUG axis. Cell Death Dis. 2020;1 1(8):644.

\section{Publisher's Note}

Springer Nature remains neutral with regard to jurisdictional claims in published maps and institutional affiliations.
Ready to submit your research? Choose BMC and benefit from:

- fast, convenient online submission

- thorough peer review by experienced researchers in your field

- rapid publication on acceptance

- support for research data, including large and complex data types

- gold Open Access which fosters wider collaboration and increased citations

- maximum visibility for your research: over $100 \mathrm{M}$ website views per year

At BMC, research is always in progress.

Learn more biomedcentral.com/submissions 